\title{
Risk factors assessment for nasal colonization of Staphylococcus aureus and its methicillin resistant strains among pre-clinical medical students of Nepal
}

\author{
Shamshul Ansari ${ }^{* *}$, Rajendra Gautam', Sony Shrestha', Safiur Rahman Ansari², Shankar Nanda Subedi ${ }^{3}$ \\ and Muni Raj Chhetri ${ }^{3}$
}

\begin{abstract}
Background: Staphylococcus aureus (S. aureus), a normal flora of nasal cavity, can cause minor to life threatening invasive diseases and nosocomial infections. Methicillin resistant strains of $S$. aureus are causing a great challenge for treatment options. Therefore, the purpose of this study was to assess the nasal carriage rate of S. aureus, its methicillin resistant strains and risk factors in medical students prior to clinical exposure.

Methods: The bacterial growth of S. aureus from nasal swab culture was identified by using standard microbiological methods recommended by American Society for Microbiology. Modified Kirby-Bauer disk diffusion method was used for antibiotic susceptibility testing and methicillin resistance was confirmed using cefoxitin and oxacillin disks. D-zone test method was used to determine the inducible clindamycin resistance.

Results: Among 200 participants, nasal carriage of S. aureus was detected from 30 (15\%) subjects. Upper respiratory tract infections significantly $(P<0.05)$ contributed the carriage of $S$. aureus and their methicillin resistant strains. All of the isolates were reported to be susceptible to vancomycin and teicoplanin. S. aureus strains detected from 8 (4 \%) students were confirmed to be methicillin resistant.
\end{abstract}

Conclusions: The result of our study demands for strict policy to screen all the students for nasal carriage of $S$. aureus and its MRSA strains to minimize the transmission of this organism from community to hospital settings.

Keywords: Medical students, MRSA, Nasal colonization, Risk factors, Staphylococcus aureus

\section{Background}

Staphylococcus aureus (S. aureus) is a normal flora of moist squamous epithelium of the anterior nares. Majority of the populations $(60 \%)$ are intermittent carriers while $20 \%$ of the population is always colonized with $S$. aureus and $20 \%$ of populations never carry this organism [1]. The evidence suggests that the populations harboring S. aureus and its methicillin resistant (MRSA) strains are at higher risk for developing invasive infection [2-4].

\footnotetext{
*Correspondence: shamshulansari483@yahoo.com

'Department of Microbiology, Chitwan Medical College, Bharatpur,

Chitwan, Nepal

Full list of author information is available at the end of the article
}

A range of minor as well as life threatening conditions like skin infections (pimples, impetigo, boils, cellulitis, folliculitis, carbuncles, scalded skin syndrome, abscesses), pneumonia, meningitis, osteomyelitis, endocarditis, toxic shock syndrome (TSS), and septicemia can be caused by S. aureus [5]. Coagulase negative Staphylococcus species (CoNS) act as the most common causative agents of nosocomial bacteremia [6].

Nasal carriage of MRSA contributes as a major risk factor for subsequent infection and transmission of this pathogen $[7,8]$. Prolonged hospitalization, antibiotics exposure, and the presence of other patients with MRSA colonization or infection in the hospital are the major risk factors for acquiring MRSA infections. MRSA 
causes life threatening infections and greater mortality than that from methicillin-sensitive S. aureus (MSSA) infections. Vancomycin, a glycopeptide antibiotic is the drug of choice to treat MRSA infections. However, the continuous use of vancomycin may promote growth of vancomycin-intermediate $S$. aureus (VISA) and vancomycin-resistant $S$. aureus (VRSA) [9]. Therefore, this study was conducted to assess the nasal carriage rate of $S$. aureus, MRSA, its antimicrobial susceptibility profile and the associated risk factors in the medical students prior to their clinical exposure.

\section{Methods}

This simple and cross-sectional study was carried out at Department of Microbiology, Chitwan Medical College (having a 600 bed teaching hospital) in the city of Bharatpur, Chitwan District, Narayani Zone, Nepal in March, 2014. A total 200 medical students who were studying in their first year of their medical education and were not exposed to their clinical posting were enrolled in this study.

\section{Data collection}

After obtaining the appropriate written consent the participants were requested to respond to a questionnaire on basic demographic characteristics (gender, residence, number of family members, profession of family, family income, family education), any potential risk factors (history of hypertension, renal disease, lower respiratory tract infection (LRTI), gastro-intestinal (GI) disease, upper respiratory tract infections (URTIs), recent surgery, recent hospitalization, recent visit to out-patient departments (OPD), any recent medication, recent antibiotic use, recent visit to hospital admitted family members) and habitual factors (vehicle used by participants, vehicle used by participants' family members, recent visit to public amusement places, tattoo or acupuncture, alcohol consumption habit, contact with livestock and pets) during swab collection.

\section{Exclusion criteria}

The participants receiving either intranasal antibiotic ointment including mupirocin, or antistaphylococcal antibiotics including clindamycin, cephalexin, cefazolin, oxacillin, dicloxacillin, trimethoprim/sulfamethoxazole, linezolid or vancomycin within 2 weeks were excluded in this study.

\section{Sample collection}

Nasal swabs were collected from both anterior nares of the students by using moist cotton swabs. Aseptic technique (disinfecting outer nostrils with alcohol) was followed while collecting the swab samples. The swab samples were transported immediately to the laboratory and processed for bacteriological profile within half an hour of collection.

\section{Microbiological study Swab processing}

For the isolation of $S$. aureus, the collected swab samples were gently rolled and streaked on the $5 \%$ sheep blood agar (BA), DNase agar and mannitol salt agar (MSA) plates (HiMedia Laboratories Pvt. Limited, India). The inoculated BA, DNase and MSA plates were incubated at $37{ }^{\circ} \mathrm{C}$ for up to $24 \mathrm{~h}$ as described in previously published article [10]. Identification of S. aureus was carried out following standard microbiological methods recommended by American Society for Microbiology (ASM) [11].

\section{Antibiotic susceptibility testing}

Modified Kirby-Bauer disk diffusion method was used for antibiotic susceptibility testing and isolates were considered either sensitive or resistant in compliance with Clinical and Laboratory Standards Institute (CLSI) guidelines [12]. Several antibiotics (HiMedia Laboratories, Pvt. Limited, India) used were: penicillin G (10 U), ciprofloxacin $(5 \mu \mathrm{g})$, gentamicin $(10 \mu \mathrm{g})$, amikacin $(30 \mu \mathrm{g})$, erythromycin $(15 \mu \mathrm{g})$, co-trimoxazole $(25 \mu \mathrm{g})$, tetracycline $(10 \mu \mathrm{g})$, rifampicin $(15 \mu \mathrm{g})$, vancomycin $(30 \mu \mathrm{g})$, teicopla$\operatorname{nin}(30 \mu \mathrm{g})$, cefoxitin $(30 \mu \mathrm{g})$, oxacillin $(1 \mu \mathrm{g})$ and clindamycin $(2 \mu \mathrm{g})$.

\section{Identification of methicillin resistant strains (MRSA)}

Disk approximation method was carried out by using oxacillin $(1 \mu \mathrm{g})$ and cefoxitin $(30 \mu \mathrm{g})$ disks for identification of methicillin resistance in $S$. aureus. The strains showing the diameter of the zone of inhibition (ZOI) of $\leq 10 \mathrm{~mm}$ with the oxacillin disk or $\leq 21 \mathrm{~mm}$ with the cefoxitin disk were recorded as methicillin resistant as recommended by CLSI [13].

\section{Identification of inducible clindamycin resistance in S. aureus}

Identification of inducible macrolide-lincosamide-streptogramin B (iMLSB) resistance in S. aureus was also performed by disk approximation method. The method involved inoculation of $S$. aureus isolate on MuellerHinton agar plate and placing clindamycin (CLI) and erythromycin (ERY) disks approximately $15 \mathrm{~mm}$ apart (measured edge to edge); the plate was then incubated for 16-18 h. The zone of inhibition around the CLI disk proximal to the ERY disk (producing a zone of inhibition shaped like the letter D) showing flattening was considered a positive result and indicates the inducible CLI resistance by ERY (a positive "D-zone test") [13]. 
S. aureus ATCC 25923 (for antibiotic sensitivity and negative control of methicillin resistance) and ATCC 43300 (for positive control of methicillin resistance) were used as a control organism [10].

\section{Statistical analysis}

Statistical analysis was performed using SPSS-16 version. Differences in proportions were assessed by Chi square test. $\mathrm{P}$ values less than 0.05 were considered statistically significant.

\section{Results}

\section{Participants and positive rates}

The participated population in this study included 200 (male 105 and female 95) students with male to female ratio of 1.1. S. aureus strains were isolated from 30 participants giving a prevalence rate of $15 \%$ and out of $30 \mathrm{~S}$. aureus strains 8 were identified as MRSA strains giving the prevalence rate of $4 \%$.

\section{Participants with socio-demographic risk factors}

Although the colonization rate in rural residents is higher (20.5\%) than urban residents (13.7\%), the association was not statistically significant. Non-significantly higher colonization rate was also found in participants having more than 4 family members (Table 1 ).

\section{Participants and potential risk factors}

Although all of the participants with LRTIs and renal disease were found colonized with $S$. aureus due to its small sample size $(\mathrm{n}=1)$, the association was not statistically significant while $25 \%$ of participants having URTIs were significantly colonized with this organism $(P=0.035)$ (Table 2).

\section{Participants and habitual risk factors}

Habitual risk factors like vehicle used by participants and their family members, recent visit to public amusement places, alcohol consumption, contact with livestock and pet did not contribute for the colonization of $S$. aureus (Table 3).

\section{Antimicrobial susceptibility testing profile}

Table 4 shows the antimicrobial resistance profile of 30 $S$. aureus strains isolated in this study. Among 30 tested isolates, resistance to penicillin $\mathrm{G}$ was most common (73.0 \%) and frequent resistance was also noted with ciprofloxacin (36.7\%). Eight (26.7\%) isolates were resistant to methicillin by cefoxitin and oxacillin disk method and $4(13.3 \%)$ isolates were found to have inducible clindamycin resistance by D-zone test. No isolates were found resistant to vancomycin and teicoplanin in this study. As
Table 1 Participants with socio-demographic characteristics

\begin{tabular}{lccc}
\hline Variables & $\begin{array}{l}\text { Total participants } \\
\text { (\%) }\end{array}$ & $\begin{array}{l}\text { Positive partici- } \\
\text { pants (\%) }\end{array}$ & P values \\
\hline $\begin{array}{l}\text { Gender } \\
\text { Male }\end{array}$ & $105(52.5)$ & $14(13.3)$ & 0.488 \\
$\begin{array}{l}\text { Female } \\
\text { Residence }\end{array}$ & $95(47.5)$ & $16(16.8)$ & \\
Rural & $39(19.5)$ & $8(20.5)$ & 0.283 \\
Urban & $161(80.5)$ & $22(13.7)$ & \\
No. of family & & & \\
members & & $17(16.0)$ & 0.660 \\
More than 4 & $106(53.0)$ & $13(13.8)$ & \\
Up to 4 & $94(47.0)$ & & \\
Profession of family & & $4(10.3)$ & \\
Health care & $39(19.5)$ & $26(16.1)$ & \\
Others & $161(80.5)$ & $1(6.7)$ & \\
Family income & & $25(16.2)$ & \\
Low & $15(7.5)$ & $4(12.9)$ & \\
Middle & $154(77.0)$ & $7(21.9)$ & \\
High & $31(15.5)$ & & \\
Family education & & & \\
Up to high school & $32(16.0)$ & $13.7)$ & \\
College & $168(84.0)$ & & \\
\hline
\end{tabular}

expected, all of the MRSA strains were resistant to penicillin G (Table 4).

\section{MRSA and associated risk factors}

MRSA strains were detected from 8 (4\%) participants. Males were more likely to carry MRSA (62.5\%) than females but association was not significant $(\mathrm{P}=0.295)$. However, URTIs, recent visit to public amusement places, contact with pet (dog) and rural type of residence were listed as significant contributing risk factors for MRSA colonization (Table 5).

\section{Discussions}

Now-a-days, the rate of urbanization is increasing in search of better life style, jobs, medical facilities and better education facilities. The result of our study also indicates that majority of the participants $(80.5 \%)$ belonged to urban area and $19.5 \%$ of the participants belonged to family having health care professions. As pets are being taken as close friends to humans, 60 (30\%) participants of our study were having pets (mostly dog). Common cold, a minor form of URTIs, is common in Nepal and thus, 44 (22\%) of the participants were suffering from upper respiratory tract infections (URTI) during the study period. 
Table 2 Participants with potential risk factors

\begin{tabular}{|c|c|c|c|}
\hline Variables & Total participants (\%) & Positive participants (\%) & $P$ values \\
\hline \multicolumn{4}{|c|}{ Hypertension } \\
\hline Yes & $4(2.0)$ & $1(25.0)$ & \multirow[t]{2}{*}{0.480} \\
\hline No & $196(98.0)$ & $29(14.8)$ & \\
\hline \multicolumn{4}{|c|}{ Renal disease } \\
\hline Yes & $1(0.5)$ & $1(100.0)$ & \multirow[t]{2}{*}{0.15} \\
\hline No & $199(99.5)$ & $29(14.6)$ & \\
\hline \multicolumn{4}{|l|}{ LRTI } \\
\hline Yes & $1(0.5)$ & $1(100.0)$ & \multirow[t]{2}{*}{0.15} \\
\hline No & $199(99.5)$ & $29(14.6)$ & \\
\hline \multicolumn{4}{|c|}{ Gastro-intestinal disease } \\
\hline Yes & $17(8.5)$ & $1(5.9)$ & \multirow[t]{2}{*}{0.477} \\
\hline No & $183(91.5)$ & $29(15.8)$ & \\
\hline \multicolumn{4}{|l|}{ URTI } \\
\hline Yes & $44(22.0)$ & $11(25.0)$ & \multirow[t]{2}{*}{0.035} \\
\hline No & $156(78.0)$ & $19(12.2)$ & \\
\hline \multicolumn{4}{|c|}{ Recent surgical procedures } \\
\hline Yes & $2(1.0)$ & $0(0)$ & \\
\hline No & $198(99.0)$ & $30(15.2)$ & \\
\hline \multicolumn{4}{|c|}{ Recent admission to hospital } \\
\hline Yes & $8(4.0)$ & $0(0)$ & \\
\hline No & $192(96.0)$ & $30(15.6)$ & \\
\hline \multicolumn{4}{|c|}{ Recent visit to out-patient departments } \\
\hline Yes & $50(25.0)$ & $4(8.0)$ & \multirow[t]{2}{*}{0.168} \\
\hline No & $150(75.0)$ & $26(17.3)$ & \\
\hline \multicolumn{4}{|c|}{ Recent medication } \\
\hline Yes & $42(21.0)$ & $7(16.7)$ & \multirow[t]{2}{*}{0.734} \\
\hline No & $158(79.0)$ & $23(14.6)$ & \\
\hline \multicolumn{4}{|c|}{ Recent antibiotic use } \\
\hline Yes & $51(25.5)$ & $8(15.7)$ & \multirow[t]{2}{*}{0.874} \\
\hline No & $149(74.5)$ & $22(14.8)$ & \\
\hline \multicolumn{4}{|c|}{ Recent visit to hospital admitted family members } \\
\hline Yes & $29(14.5)$ & $6(20.6)$ & \multirow[t]{2}{*}{0.354} \\
\hline No & $171(85.5)$ & $24(14.0)$ & \\
\hline
\end{tabular}

Recent-in last 3 months

Although, large proportion of $S$. aureus carriage is through the anterior nares of the nasal passages, it can be found on the skin of the host [1]. The combination of defective host immunity and the bacterial ability to evade host innate immunity results in the ability of the nasal passages to harbor S. aureus [14]. Approximately $20 \%$ of individuals act as persistent carriers and almost always carry one type of strain [15]. In this study, we detected $15 \%$ nasal carriage of $S$. aureus in medical students, similar to the rates detected from Malaysia $[16,17]$ and Iraq [18].

In this study, a non-significant association was observed between the $S$. aureus colonization and type of residence. The present analysis found that $73.3 \%$ of the students positive for nasal colonization of $S$. aureus were from cities and $83.3 \%$ of participants used public vehicle for travelling. The changing pattern of life style in urban area like frequent visit of shopping malls and theatres, attending parties and travelling via public vehicles bring peoples to be in close contact and easily can transmit the pathogens to others. Moreover, contaminated door handles of public vehicles also act as source infections.

Although, non-significant association was observed between nasal carriage of $S$. aureus and clinical factors such as medication and antibiotic use in last 3 months, there was significant association $(P=0.035)$ with upper 
Table 3 Participants with habitual risk factors

\begin{tabular}{|c|c|c|c|}
\hline Variables & Total participants (\%) & Positive participants (\%) & $P$ values \\
\hline \multicolumn{4}{|c|}{ Vehicle used by participants } \\
\hline Public & $168(84.0)$ & $25(14.9)$ & \multirow[t]{2}{*}{0.920} \\
\hline Personal & $32(16.0)$ & 5 (15.6) & \\
\hline \multicolumn{4}{|c|}{ Vehicle used by participant's family members } \\
\hline Public & $82(41.0)$ & $12(14.6)$ & \multirow[t]{2}{*}{0.904} \\
\hline Personal & $118(59.0)$ & $18(15.3)$ & \\
\hline \multicolumn{4}{|c|}{ Recent visit to public amusement places } \\
\hline Yes & $106(53.0)$ & $12(11.3)$ & \multirow[t]{2}{*}{0.122} \\
\hline No & $94(47.0)$ & $18(19.1)$ & \\
\hline \multicolumn{4}{|c|}{ Tattoo or acupuncture } \\
\hline Yes & $0(0)$ & $0(0)$ & \\
\hline No & $200(100)$ & $30(15.0)$ & \\
\hline \multicolumn{4}{|c|}{ Alcohol consumption habit } \\
\hline Yes & $5(2.5)$ & $1(20.0)$ & \multirow[t]{2}{*}{0.560} \\
\hline No & $195(97.5)$ & $29(14.9)$ & \\
\hline \multicolumn{4}{|c|}{ Contact with livestock } \\
\hline Yes & $26(13.0)$ & $2(7.7)$ & \multirow[t]{2}{*}{0.263} \\
\hline No & $174(87.0)$ & $28(16.0)$ & \\
\hline \multicolumn{4}{|c|}{ Contact with pets } \\
\hline Yes & $60(30.0)$ & $9(15.0)$ & \multirow[t]{2}{*}{1.0} \\
\hline No & $140(70.0)$ & $21(15.0)$ & \\
\hline
\end{tabular}

Table 4 Antibiotic resistance pattern of S. aureus and MRSA

\begin{tabular}{lll}
\hline Antibiotics & $\begin{array}{l}\text { S. aureus }(\mathbf{n}=\mathbf{3 0}) \\
\text { Resistant frequency (\%) }\end{array}$ & $\begin{array}{l}\text { MRSA }(\mathbf{n}=\mathbf{8}) \\
\text { Resistant frequency (\%) }\end{array}$ \\
\hline Penicillin G & $22(73)$ & $8(100)$ \\
Ciprofloxacin & $11(36.7)$ & $6(75.0)$ \\
Gentamicin & $10(33.3)$ & $5(62.5)$ \\
Amikacin & $3(10)$ & $1(12.5)$ \\
Erythromycin & $10(33.3)$ & $5(62.5)$ \\
Cotrimoxazole & $6(20)$ & $4(50.0)$ \\
Tetracycline & $6(20)$ & $3(37.5)$ \\
Rifampicin & $6(20)$ & $3(37.5)$ \\
Vancomycin & 0 & 0 \\
Teicoplanin & 0 & 0 \\
Cefoxitin & $8(26.7)$ & $8(100)$ \\
Oxacillin & $8(26.7)$ & $8(100)$ \\
Clindamycin & $8(26.7)$ & $3(37.5)$ \\
\hline
\end{tabular}

respiratory tract (nasal) infections in our study. Studies from other settings have also reported increased spread of $S$. aureus during an episode of URTIs [19]. In a study conducted from Malaysia, $22.5 \%$ cases of nasal carriage were associated with URTIs and $9.9 \%$ cases were associated with recent antibiotic use [17].

The reports of recent study have documented that S. aureus can survive on dogs and cats [20,21]. Some authors believe that health-care workers' dogs should be considered a significant source of antibiotic-resistant S. aureus, especially during outbreaks [20]. In our study, we found that $30 \%$ of the nasal carriers of S. aureus have had contact with pet (mostly dog), the findings being much lower than the result of $77 \%$ from Virginia [22]. The lower rate of our study may be due to the rather still uncommon practice of domesticating pets in Nepal than others.

Although, the overall resistance rates to commonly prescribed antibiotics in isolates were below $50 \%$, as expected the rate was high (73\%) with penicillin because only a small proportion of the $S$. aureus lineages do not produce beta-lactamases [23-26]. Similarly, a higher rate of resistance (92\%) to ampicillin was also reported in a study conducted in Brazil [27].

Ciprofloxacin became the most widely used quinolone antibiotic after its introduction into clinical use in the late 1980 s and early 1990s [28, 29]. In recent years, resistance has been developed in many bacteria, making it significantly less effective [30, 31]. We identified ciprofloxacin resistance rate of $36.7 \%$ in this study much higher than the result $(8.8 \%)$ from Brazil [27]. This high rate of resistance in our study may be because of its indiscriminate use in our setting as a consequence of low cost and easy availability. Once effective against staphylococcal infections, the aminoglycoside antibiotics such as kanamycin, 
Table 5 Risk factors and MRSA positive cases $(\mathbf{N}=\mathbf{8})$

\begin{tabular}{|c|c|c|}
\hline Variables & Positive numbers $(n=8)$ & $P$ value \\
\hline \multicolumn{3}{|l|}{ Gender } \\
\hline Male & 5 & 0.295 \\
\hline Female & 3 & \\
\hline \multicolumn{3}{|l|}{ Co-morbidities } \\
\hline URTIS & 6 & 0.009 \\
\hline Others & 2 & \\
\hline \multicolumn{3}{|c|}{$\begin{array}{l}\text { Recent visit to hospital admitted } \\
\text { family members }\end{array}$} \\
\hline Yes & 1 & 0.536 \\
\hline No & 7 & \\
\hline \multicolumn{3}{|c|}{$\begin{array}{l}\text { Recent visit to public amusement } \\
\text { places }\end{array}$} \\
\hline Yes & 6 & 0.018 \\
\hline No & 2 & \\
\hline \multicolumn{3}{|l|}{ Contact with pet } \\
\hline Yes (dog) & 6 & 0.0005 \\
\hline No & 2 & \\
\hline \multicolumn{3}{|l|}{ Type of residence } \\
\hline Urban & 3 & 0.007 \\
\hline Rural & 5 & \\
\hline \multicolumn{3}{|c|}{$\begin{array}{l}\text { Vehicle used by participant's family } \\
\text { member }\end{array}$} \\
\hline Personal & 5 & 0.866 \\
\hline Public & 3 & \\
\hline \multicolumn{3}{|l|}{ Profession of family } \\
\hline Health care & 2 & 0.257 \\
\hline Other than health care & 6 & \\
\hline \multicolumn{3}{|l|}{ Family income } \\
\hline Middle & 8 & 0.140 \\
\hline Others & 0 & \\
\hline
\end{tabular}

gentamicin, streptomycin etc., have been found less effective because of the development of mechanisms to inhibit the action, which occurs via protonated amine and/or hydroxyl interactions with the ribosomal RNA of the bacterial $30 \mathrm{~S}$ ribosomal subunit [32]. As a consequence of low cost and easy availability, there has been indiscriminate use of this antibiotic similarly as with ciprofloxacin in our context. We observed the rate of gentamicin resistance as $33.3 \%$ and amikacin resistance as $10 \%$. Similar rate of gentamicin resistance ( $25 \%$ ) was also detected by Sharma et al. [33] whereas lower rate of amikacin resistance (4\%) was also reported from Brazil [27].

Today, the therapeutic roles of erythromycin and trimethoprim-sulfamethoxazole (co-trimoxazole) are increasingly limited due to its extensive use for the treatment of both minor and serious staphylococcal infections. One third (33.3\%) of our isolates were resistant to erythromycin and $20 \%$ isolates were resistant to co-trimoxazole, the results are in agreement with the reported finding from Iran [34].

Glycopeptides like vancomycin and teicoplanin could be reserved for the management of MRSA infections because of its high efficacy in virtually all isolates of $S$. aureus $[35,36]$. The result of susceptibility in the current study to vancomycin and teicoplanin is comparable to that of other studies conducted worldwide [18, 27, 33]. The promising efficacy of glycopeptides is probably due to high cost and low usage of these regimens in Nepal. However, increased resistance to teicoplanin has been reported overseas [37-40]. Thus, glycopeptides especially vancomycin can be used empirically for serious staphylococcal infections while waiting for susceptibility testing results to come through [41].

Methicillin, the first antibiotic of $\beta$-lactamase-resistant penicillins (methicillin, oxacillin, cloxacillin, and flucloxacillin) was detected to be ineffective only after two years of its introduction (introduced in 1959) in England and it was the first case of MRSA [42]. Then until 1990s, when there was an explosion in MRSA prevalence in hospitals, MRSA generally remained an uncommon finding, [43]. In present study, two different methods, the cefoxitin disk and oxacillin disk methods were employed for the detection of MRSA. According to CLSI guidelines, the mecA mediated resistance to oxacillin can be detected by using cefoxitin disk or oxacillin disk method but cefoxitin disk method is more preferred because it is easier to read and also cefoxitin acts as an inducer of the $m e c A$ gene [13]. Results of the present study indicated that, $4 \%(8 / 200)$ students harbored the MRSA in their nasal cavity. Similarly, $6 \%$ MRSA carriage rate in medical students before clinical exposure was also detected from India [44].

Macrolide-resistant isolates of $S$. aureus may be resistant to only macrolides mediated by efflux mechanism encoded by the $m s r A$ gene or may have constitutive or inducible resistance to clindamycin mediated by methylation of the 23S rRNA encoded by the erm gene [13]. Clindamycin is considered as one of the drugs of choice in $S$. aureus infections but an erm gene mediated inducible resistance may result in treatment failure [45]. In our study, we identified 4 isolates (13.3\%) as D-zone test positive, indicating inducible resistance to clindamycin. Similar result of inducible resistance to clindamycin was also reported from Nepal [10].

Spread of S. aureus (including MRSA) is generally through human-to-human contact, although recently some veterinarians have documented that the infection can also spread through pets [46]. In a case control study, $73 \%$ of MRSA were recovered from pets (cat, dog and other rodents) [22]. Similarly, in our study we observed that $75 \%$ of MRSA carriers have had contact 
with pet especially dog. High proportion of MRSA (75 \%) colonization was also significantly associated with URTIs $(P=0.009)$ and visit to public amusement places $(P=0.018)$. Although the resident type was not associated with the colonization rate of S. aureus, it did the colonization of MRSA in our study $(\mathrm{P}=0.007)$.

Our study had a few limitations, we selected a limited pool of antibiotics for susceptibility testing and molecular studies could not performed to confirm MRSA isolates due to financial constraints.

\section{Conclusions}

The result of this study highlights the nasal carriage of $S$. aureus and their methicillin resistant counterparts in the medical students. This study indicates that carriage of this organism has no significant association with sociodemographic and habitual risk factors. However, URTIs can enhance the carriage of $S$. aureus as well as their MRSA strains. Recent visit to public amusement places, contact with dog (pet) and rural residence were also documented as the significant risk factors contributing the MRSA colonization. The colonization of $S$. aureus and MRSA can play a key role in the epidemiology and pathogenicity of community as well as hospital associated infections. From this study, the longitudinal surveillance of nasal carriage of $S$. aureus should be made an essential protocol to minimize the transmission of this organism from community to hospital and vice versa.

\begin{abstract}
Abbreviations
MRSA: methicillin resistant Staphylococcus aureus; MSSA: methicillin susceptible Staphylococcus aureus; VRSA: vancomycin resistant Staphylococcus aureus; VISA: vancomycin intermediate Staphylococcus aureus; ATCC: American type culture collection; OPD: outpatient department; URTIs: upper respiratory tract infections; LRTIs: lower respiratory tract infections; Gl: gastrointestinal; ASM: American Society for Microbiology; TSS: toxic shock syndrome; CLSI: Clinical and Laboratory Standard Institute; BA: blood agar; MSA: mannitol salt agar; ZOI: zone of inhibition; IRC: Institutional Review Committee.
\end{abstract}

\section{Authors' contributions}

SA conceived the design of the study and performed the experiments with help from SS. RG prepared the draft of the manuscript. SRA and SNS performed the statistical analysis and searched the published literatures. SA and RG prepared the final draft of the manuscript and MRC guided the manuscript preparation. All authors read and approved the final manuscript.

\section{Author details}

${ }^{1}$ Department of Microbiology, Chitwan Medical College, Bharatpur, Chitwan, Nepal. ${ }^{2}$ Asian College for Advanced Studies, Satdobato, Kathmandu, Nepal. ${ }^{3}$ Department of Community Medicine and Public Health, Chitwan Medical College, Bharatpur, Chitwan, Nepal.

\section{Acknowledgements}

We, the authors, would like to express our sincere thanks to all the students of Chitwan Medical College for participating in this study. We are also thankful to laboratory staffs for their kind support in the bacteriological investigations.

\section{Competing interests}

The authors declare that they have no competing interests.

\section{Ethical approval}

The written informed consent for the study was obtained from each participants enrolled in this study. Ethical approval to conduct the study was obtained from the Institutional Review Committee of Chitwan Medical College (IRC-CMC), Bharatpur, Chitwan, Nepal.

Received: 2 September 2015 Accepted: 3 April 2016

Published online: 12 April 2016

\section{References}

1. Kluytmans J, Van Belkum A, Verbrugh H. Nasal carriage of Staphylococcus aureus: epidemiology, underlying mechanisms, and associated risks. Clin Microbiol Rev. 1997;10(3):505-20.

2. Peacock SJ, De-Silva I, Lowy FD. What determines nasal carriage of Staphylococcus aureus? Trends Microbiol. 2001;9:605-10.

3. Von-Eiff C, Becker K, Machka K, Stammer H, Peters G. Nasal carriage as a source of Staphylococcus aureus bacteremia. N Eng J Med. 2001;344:11-6.

4. Williams REO. Healthy carriage of Staphylococcus aureus: its prevalence and importance. Bacteriol Rev. 1963;27:56-71.

5. John B. Experimental staph vaccine broadly protective in animal studies. $\mathrm{NIH}$. Archived from the original on 5 May 2007. Retrieved 28 July 2007.

6. Topley WWC, Wilson GS. Topley and Wilson's principle of bacteriology, virology and immunology. Parker MT, Collier LH (Gen eds), 8th edition. London: Edward Arnold. 1990.

7. Kluytmans J, Van-Belkum A, Verbrugh H. Nasal carriage of Staphylococcus aureus: epidemiology, underlying mechanisms, and associated risks. Clin Microbiol Rev. 1997;10:505-20.

8. Wertheim HF, Melles DC, Vos MC, et al. The role of nasal carriage in Staphylococcus aureus infections. Lancet Infect Dis. 2005;5:751-62.

9. Kenrad EN. Infectious disease epidemiology: theory and practice. Am J Epidemiol. 2008;2:509-34.

10. Ansari S, Nepal HP, Gautam R, Raymajhi N, Shrestha S, Upadhyay G, Acharya A, Chapagain ML. Threat of drug resistant Staphylococcus aureus to health in Nepal. BMC Infect Dis. 2014;14:157.

11. Isenberg HD. Clinical microbiology procedures handbook. 2nd ed. Washington: ASM Press; 2004.

12. Clinical and Laboratory Standard Institute (CLSI). Performance standards for antimicrobial susceptibility testing. Wayne: CLSI; 2006 (M100-S16).

13. Clinical and Laboratory Standards Institute (CLSI). Performance standards for antimicrobial susceptibility testing, 17th informational supplement. Wayne: CLSI; 2007 (M100-S17).

14. Quinn GA, Cole AM. Suppression of innate immunity by a nasal carriage strain of Staphylococcus aureus increases its colonization on nasal epithelium. Immunology. 2007;122(1):80-9.

15. Armstrong-Esther CA. Carriage patterns of Staphylococcus aureus in a healthy non-hospital population of adults and children. Ann Hum Biol. 1976;3(3):221-7.

16. Neela V, Alshrari ASD, Rad EG, Moghaddam HG, Van-Belkum A, Alreshidi MA, et al. Highly dynamic transient colonization by Staphylococcus aureus in healthy Malaysian students. J Med Microbiol. 2009;58(11):1531-2.

17. Syafinaz AM, Nur-Ain NZ, Nadzirahi SN, Fatimah JS, Shahram A, Nasir MD. Staphylococcus aureus nasal carriers among medical students in a medical school. Med J Malays. 2012;67(6):636-8.

18. Habeeb A, Hussein NR, Assafi MS, Al-Dabbagh SA. Methicillin resistant Staphylococcus aureus nasal colonization among secondary school students at Duhok city-Iraq. J Microbiol Infect Dis. 2014;4(2):59-63.

19. Sherertz RJ, Bassetti S, Bassetti-Wyss B. "Cloud" health care workers. Emerg Infect Dis. 2001;7(2):241-4.

20. Boost MV, O'donoghue MM, James A, O'donoghue J. Prevalence of Staphylococcus aureus carriage among dogs and their owners. Epidemiol Infect. 2008;136(7):953-64.

21. Hanselman BA, Kruth SA, Rousseau J, Weese JS. Coagulase positive staphylococcal colonization of humans and their household pets. Can Vet J. 2009;50(9):954-8.

22. Millerr MB, Weber DJ, Goodrich JS, Popowitch EB, Poe MD, Nyugen V, et al. Prevalence and risk factor analysis for methicillin-resistant Staphylococcus 
aureus nasal colonization in children attending child care centers. J Clin Microbiol. 2011;49(3):1041-7.

23. Tiwari HK, Das AK, Sapkota D, Sivarajan K, Pahwa VK. Methicillin resistant Staphylococcus aureus: prevalence and antibiogram in a tertiary care hospital in western Nepal. J Infect Dev Ctries. 2009;3(9):681-4.

24. Shakya B, Shrestha S, Mitra T. Nasal carriage rate of methicillin resistant Staphylococcus aureus among at National Medical College Teaching Hospital, Birgunj, Nepal. Nepal Med Coll J. 2010;12(1):26-9.

25. Mishra SK, Rijal BP, Pokhrel BM. Emerging threat of multidrug resistant bugs-Acinetobacter calcoaceticus baumannii complex and methicillin resistant Staphylococcus aureus. BMC Res Notes. 2013;6:98-103.

26. Sanjana RK, Shah R, Chaudhary N, Singh YI. Prevalence and antimicrobial susceptibility pattern of methicillin-resistant Staphylococcus aureus (MRSA) in CMS-teaching hospital: a preliminary report. J Coll Med Sci (Nepal). 2010;6(1):1-6.

27. Prates KA, Torres AM, Garcia LB, Ogatta SFY, Cardoso CL, Tognim MCB. Nasal carriage of methicillin-resistant Staphylococcus aureus in university students. Braz J Infect Dis. 2010;14(3):316-8.

28. Goossens H, Ferech M, Coenen S, Stephens P. Comparison of outpatient systemic antibacterial use in 2004 in the United States and 27 European countries. Clin Infect Dis. 2007;44(8):1091-5.

29. BC Centre for Disease Control. British Columbia annual summary of antibiotics utilization 2010. http://www.bccdc.ca/nr/rdonlyres/179736e952a0-4d7e-b2e7-ed416f4ea427/0/executivesummary2010antibioticconsumptionreport_aug (2012).

30. Vatopoulos AC, Kalapothaki V. Bacterial resistance to ciprofloxacin in Greece: results from the national electronic surveillance system. Emerg Infect Dis. 1999;5(3):471-6.

31. Paul ST. Bacterial resistance prompts concern among health officials. The Minnesota department of health issued the following news release. http://www.highbeam.com/doc/1p3-1653270211.html (2009).

32. Carter AP, Clemons WM, Brodersen DE, Morgan-Warren RJ, Wimberly BT, Ramakrishnan V. Functional insights from the structure of the $30 \mathrm{~s}$ ribosomal subunit and its interactions with antibiotics. Nature. 2000;407(6802):340-8.

33. Sharma $Y$, Jain $S$, Singh $H$, Govil V. Staphylococcus aureus: screening for nasal carriers in a community setting with special reference to MRSA. Scientifica. 2014;2014:479048. doi:10.1155/2014/479048

34. Soltani B, Ardakani AT, Moravveji A, Erami M, Rezaei MH, Moniri R, et al. Risk factors for methicillin resistant Staphylococcus aureus nasal colonization of healthy children. Jundishapur J Microbiol. 2014;7(9):e20025. doi:10.5812/jjm.20025.

35. Adwan K, Jarrar N, Abu-Hijleh A, et al. Molecular analysis and susceptibility patterns of methicillin-resistant Staphylococcus aureus strains causing community and health care associated infections in the Northern region of Palestine. Am J Infect Control. 2013;41:195-8.

36. Hassan AN, Hashim EA, Musa OH, Elsayed DE. Staphylococcus aureus nasal carriage among surgical personnel in National Ribat University Teaching Hospital-Khartoum, Sudan. Sudan J Med Sci. 2008;3:281-4.

37. Cormican MG, Jones RN. Emerging resistance to antimicrobial agents in gram-positive bacteria. Drugs. 1996;51:6-12.

38. Shittu AO, Lin J. Antimicrobial susceptibility patterns and characterization of clinical isolates of Staphylococcus aureus in KwaZulu-Natal province, South Africa. BMC Infect Dis. 2006;6:125-37.

39. Centers for disease control and prevention (CDC). Staphylococcus aureus resistance to vancomycin in the United States of America. MMWR. 2002;51:565-7.

40. Classen M, Nouwe J, Fang N, Ott A, Verbrugh H, Hofman A, Vanbelkum A, Uitterlinder A. Staphylococcus aureus nasal carriage is not associated with known polymorphism in the vitamin D receptor gene. FEMS Immunol Med Microbiol. 2005;43:173-6.

41. Sader HS, Gales AC, Jones RN. Antimicrobial activity of linezolid against gram-positive cocci isolated in Brazil. Braz J Infect Dis. 2001;5:171-6.

42. Jevons MP. Celbenin-resistant staphylococci. Br Med J. 1961;1(5219):124-5

43. Johnson AP, Aucken HM, Cavendish S, Ganner M, Wale MC, Warner M, et al. Dominance of EMRSA-15 and -16 among MRSA causing nosocomial bacteraemia in the UK: analysis of isolates from the European Antimicrobial Resistance Surveillance System (EARSS). J Antimicrob Chemother. 2001;48(1):143-4.

44. Rao TV, Babin D. Detection of MRSA in medical and nursing students not exposed to patient care environment. Glob Res Anal. 2013;2(8):157-8.

45. Lim HS, Lee $H$, Roh KH, Yum JH, Yong D, Lee K, et al. Prevalence of inducible clindamycin resistance in staphylococcal isolates at a Korean tertiary care hospital. Yonsei Med J. 2006;47:480-4.

46. Sing A, Tuschak C, Hoermansdorfer S. Methicillin-resistant Staphylococcus aureus in a family and its pet cat. N Engl J Med. 2008;358(11):1200-1.

\section{Submit your next manuscript to BioMed Central and we will help you at every step:}

- We accept pre-submission inquiries

- Our selector tool helps you to find the most relevant journal

- We provide round the clock customer support

- Convenient online submission

- Thorough peer review

- Inclusion in PubMed and all major indexing services

- Maximum visibility for your research

Submit your manuscript at www.biomedcentral.com/submit
() Biomed Central 